\title{
A CASE OF OSTEITIS FIBROSA CYSTICA (OSTEOMALACIA?) WITH EVIDENCE OF HYPERACTIVITY OF THE PARA- THYROID BODIES. METABOLIC STUDY I ${ }^{1}$
}

By R. R. HANNON, E. SHORR, W. S. McCLELLAN ANd E. F. DuBOIS

(From the Russell Sage Institute of Pathology in affiliation with the Second Medical (Cornell) Division of Bellevue Hospital, New York)

(Received for publication July 15, 1929)

The history, general discussion and outstanding features of osteitis fibrosa cystica may be found in any system of medicine $(1,2)$. The mineral metabolism of osteitis fibrosa cystica and related diseases, such as osteomalacia and rickets, where there is a disturbance in the physiology of inorganic salt deposit has received much attention recently.

In January 1926, a patient showing evidence of marked bone absorption with little replacement of calcium was admitted to Bellevue Hospital. Extensive studies of this rare condition were made in the metabolism wards of the Russell Sage Institute of Pathology, New York, and of the Massachusetts General Hospital, Boston. This article will present a clinical résumé of the case with the various findings of the first period of observation.

\section{CASE REPORT}

History. The patient Charies M., age 30, was admitted to Bellevue Hospital January 15, 1926. He was a master mariner in the merchant marine and in 1918 was navigating officer of a transport. He was at that time in fine physical condition, an active athlete, 6 feet 1 inch tall. His habits were good, his medical history uneventful and during his war service he was subjected at times to the nervous strain of navigating in the war zone. There were periods when his diet was low in calcium as he had almost no milk, eggs or green vegetables. In November 1918 when 22 years old, he slipped and felt a sharp, severe pain in his right loin which lasted one week. Three months later pains were felt in the legs and hips, which became more severe, and extended upward to the lumbar spine.

\footnotetext{
${ }^{1}$ Presented in abstract before the Interurban Clinical Club, New York, April, 1927.
} 
About July 1919, his fellow officers noted that he was growing shorter and becoming pigeon breasted. His neck shortened and thickened so that he had to wear larger collars. About the same time he noticed that he sometimes passed thick white gravel at the end of urination and that the urine was very cloudy. The passing of the gravel caused severe pain. The occurrence of gravel continued until 1925. His right patellar ligament was ruptured in 1920. He stumbled easily because he had difficulty in coördinating muscular movements. Pains in the heels, legs, and back were caused by the jars of walking, or coming down stairs. He became so weak that he could hardly climb stairs. Despite these disabilities he remained at sea until 1922 when he was obliged to return to New York for treatment on account of abdominal pain and vomiting. He was then 5 feet $8 \frac{1}{2}$ inches tall. He was treated for one year for arthritis with no improvement.

In October 1923, he stumbled, fell against a chair, and broke both bones of the left forearm. A roentgenogram taken then showed considerably decreased density of the bones suggesting osteomalacia. He was admitted to the Marine Hospital, Staten Island, in December 1923, where he remained as a patient until November 1925. His fractured left arm was kept in a cast for 9 months before union occurred. While in the hospital in August 1924 he fractured the left radius and in October 1925, the right humerus. He was placed on a Bradford frame with traction to secure extension and his height increased to 5 feet 9 inches. When he was allowed up he measured 5 feet 6 inches, after 30 minutes in an erect position. Then he wore a supporting body brace. The next deformities which appeared were a shortening of the neck, a sinking of the head, and a forward protrusion of the lower jaw. Roentgenograms taken in the Marine Hospital showed osteomalacia involving the whole skeletal system. While there he was given diets high in calcium and phosphorus, cod liver oil, calcium and phosphorus medications, thyroid extracts, epinephrin, heliotherapy, quartz lamp treatment, and irradiated milk, without noticeable improvement. During his stay in the hospital he felt weak and suffered almost constantly from pain in his bones and joints.

In the six weeks between his discharge from the Marine Hospital and his admission to Bellevue Hospital his pains gradually wore away and the urinary gravel nearly disappeared.

Physical examination. The general appearance can best be shown by the front and side views of the patient. (Fig. 1.) He was well nourished. His head showed exaggerated grooves and prominences of the calvareum and a protruding lower jaw. The teeth were in good condition. There were no evidences of infection of the throat. The neck was short and thick with no enlargement of the thyroid. The chest showed a marked prominence of the sternum. The ribs impinged on the iliac crests. The heart was normal in rate and rhythm. There was an appendectomy scar in the right lower abdominal quadrant. The external genitals were normal. The spine was rigid, with marked kyphosis in upper dorsal region and with considerable tenderness on pressure in the lumbar region. His ex- 


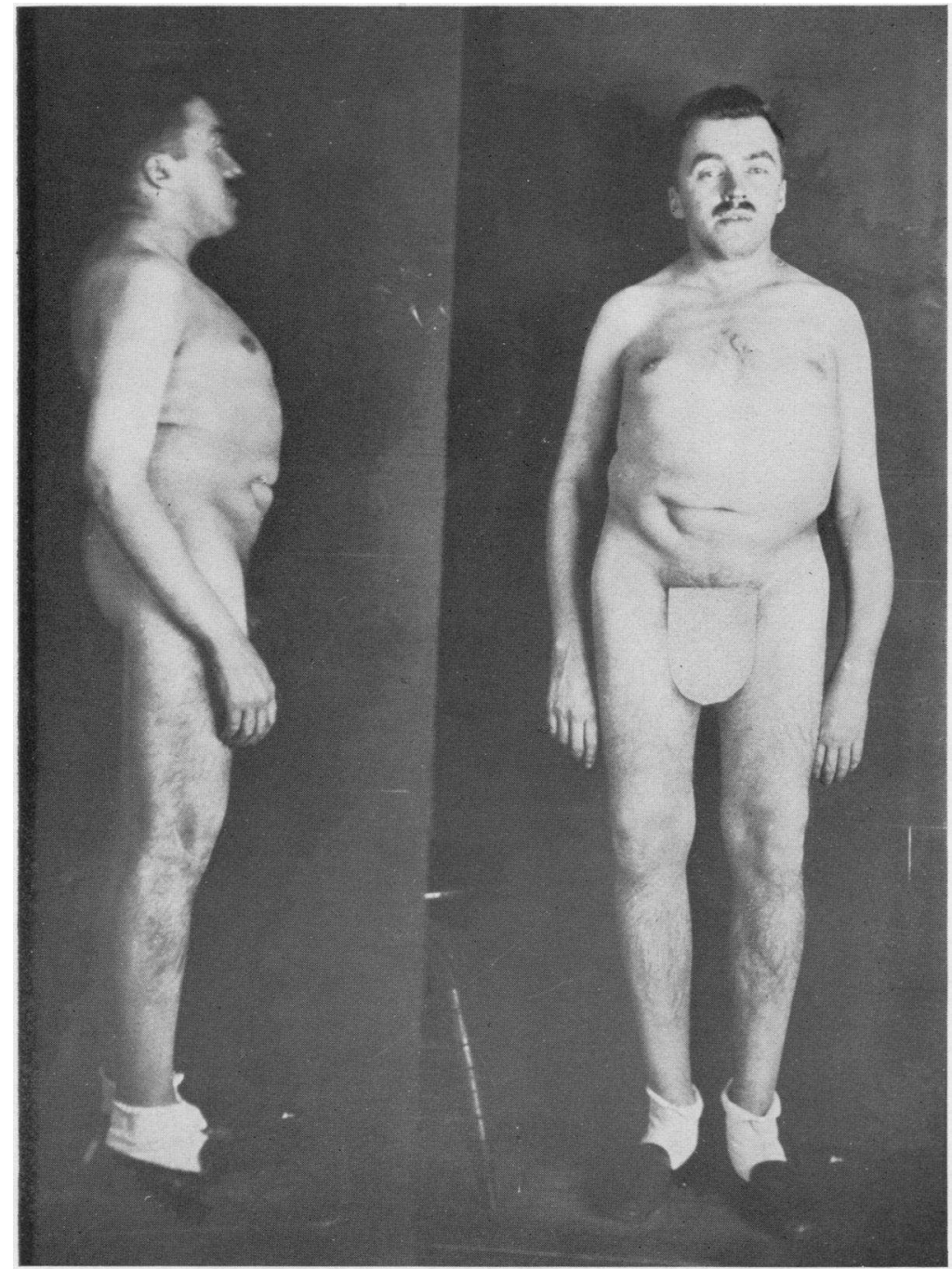

Fig. 1. Front and Side Views of the Patient Charles M., January, 1926, Showing the Protruding Jaw, Short Neck, Deformed Chest and Contour of Extremities 


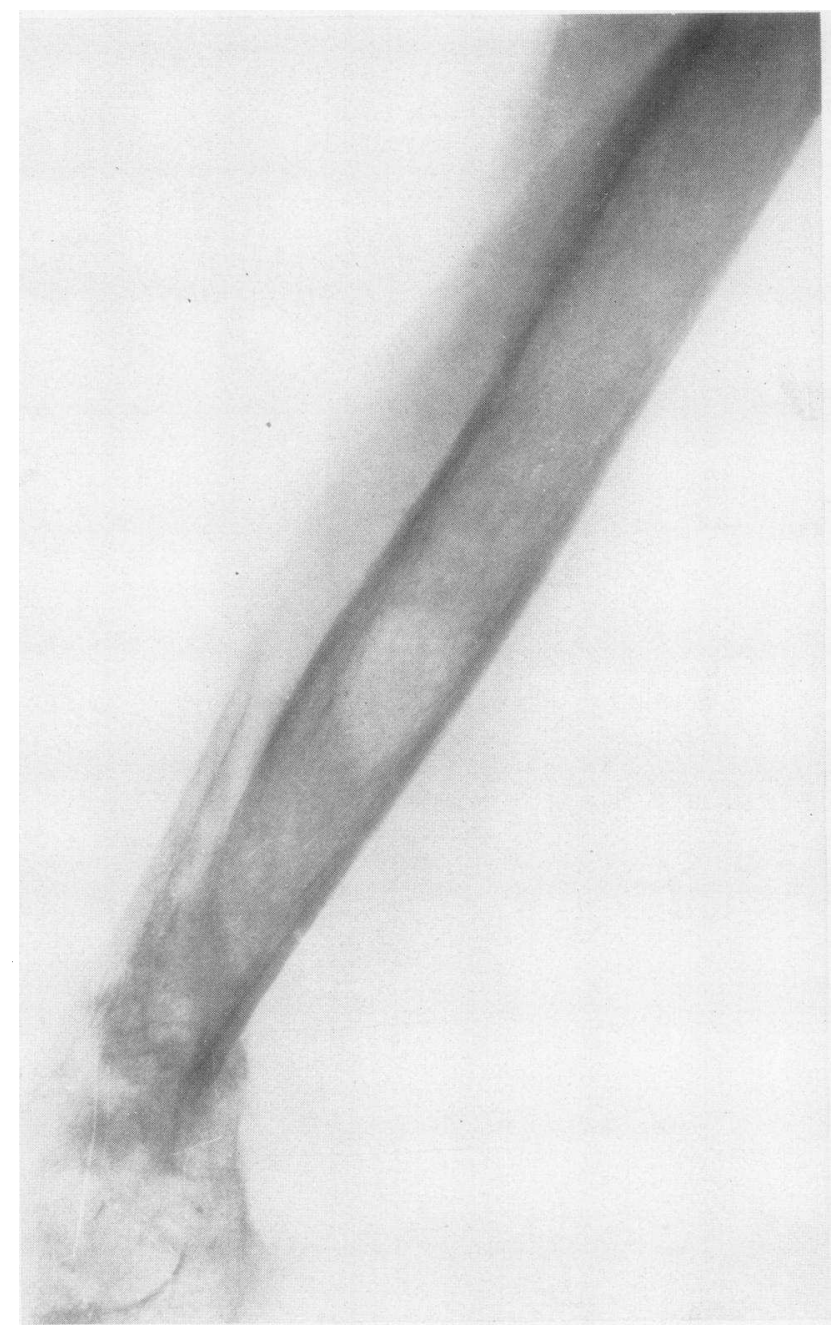

Fig. 2. Roentgenogram of Right Humerus and Elbow, January, 1926, Showing Atrophy, Fracture in Lower end of Humerus, and a Small Cyst 
tremities showed bowing deformities in both arms due to old fractures with some tenderness on pressure over the bones. The muscles generally were soft and flabby with apparent loss of tone. The knee jerks were present but sluggish.

Laboratory data. The temperature varied between $98^{\circ}$ and $99^{\circ} \mathrm{F}$., the pulse between 70 and 90 per minute and the respirations between 18 and 24 per minute.

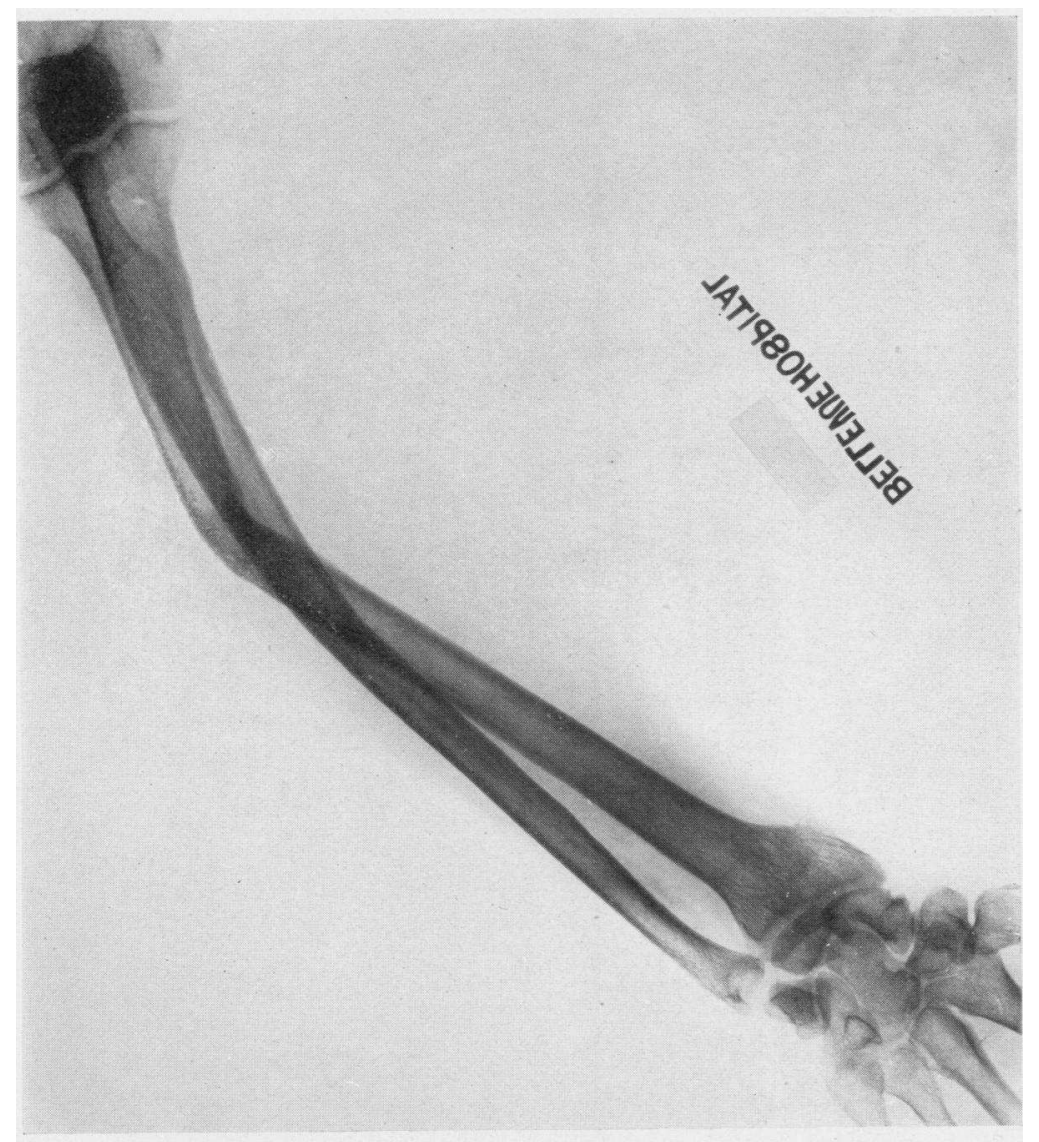

Fig. 3. Roentgenogram of Left Radius and Ulna, January, 1926, Showing MaRked Bowing AND Deformity

The blood pressure ranged from 110 to 125 , systolic, and 65 to 80 diastolic. His weight remained between 64.5 and $66.8 \mathrm{kgm}$. The urine was clear, amber, acid in reaction with specific gravity of 1,020 and was negative for glucose, albumen, blood and casts. The blood Wassermann was negative, the hemoglobin 95 per 


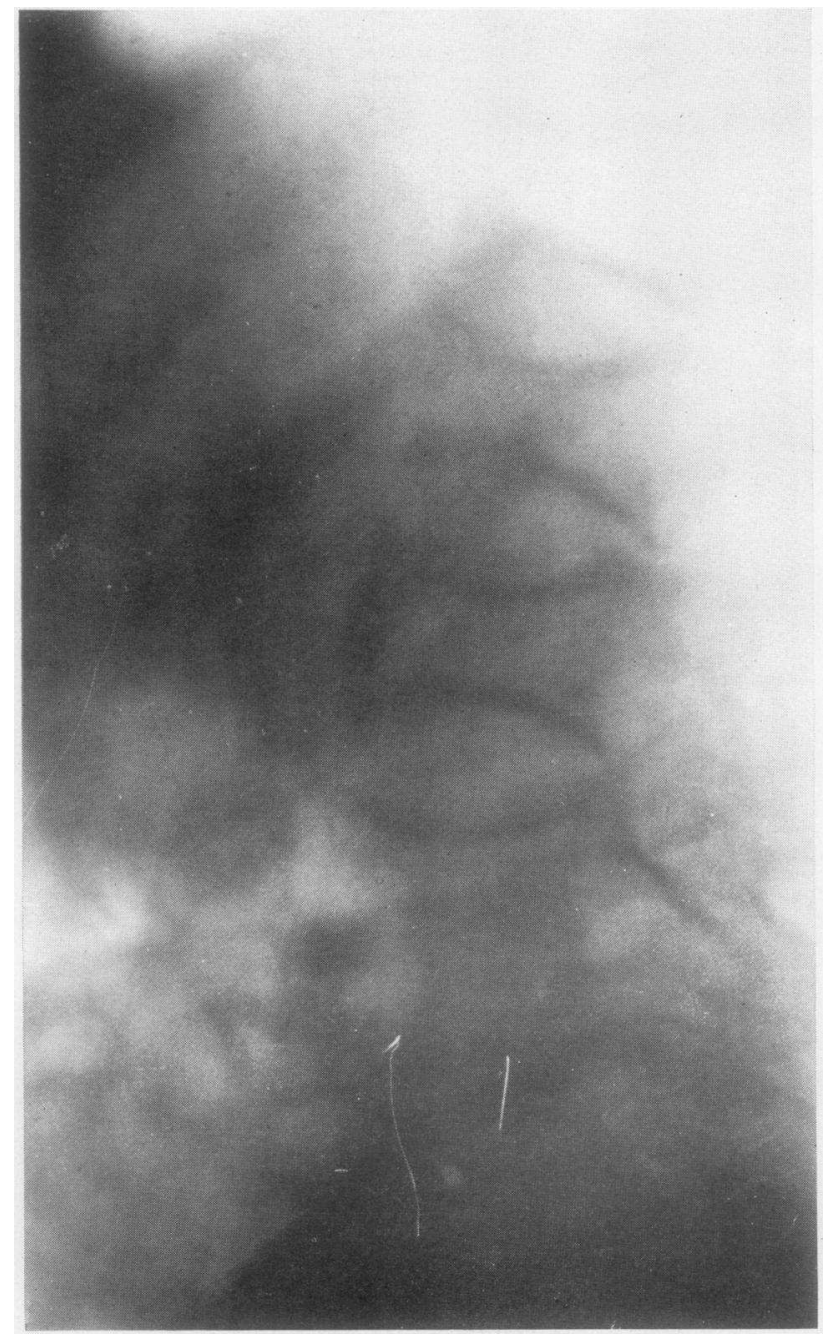

Fig. 4. Roentgenogram of Lumbar Spine, Lateral View, January, 1926, Showing Curvature, Widened Intervertebral Disks, and Narrowed Bodies of the Vertebra 
cent and the white blood count 7,400 with a differential count showing 62 per cent polymorphonuclears, 30 per cent lymphocytes, 6 per cent large mononuclears and 1 per cent each eosinophiles and basophiles. The blood chemistry on January 20, 1926 was: non-protein nitrogen $36 \mathrm{mgm}$. per $100 \mathrm{cc}$., uric acid $3.5 \mathrm{mgm}$. sugar $98 \mathrm{mgm}$., serum calcium $14.5 \mathrm{mgm}$., serum phosphorus $3.3 \mathrm{mgm}$. and carbon dioxide combining power 56 volumes per cent. The blood on standing formed a soft, friable, dark red clot which retracted only slightly in 24 hours. The basal metabolism was -8 to -17 per cent by Aub-Du Bois standards.

Roentgenograms of the bones showed the following changes. There was extensive bone atrophy with absorption of the cortex, a few cystic formations and marked bony deformities particularly in the pelvis and spine. The skull was involved in these changes. Figure 2 shows the right humerus and elbow, figure 3 the left radius and ulna, and figure 4 a lateral view of the lumbar spine. The electrical reactions were, galvanic, K.C.C. 55 m.a., A.C.C. 60 m.a. and faradic 14 m.a. These findings were about twice the amount of current required to produce a reaction normally and represent a considerable diminution in the electrical excitability of muscle and nerve.

Course in hospital. After about 3 weeks of preliminary observations, exact metabolic balance studies were begun, and continued for 76 days, with accurately weighed diets and complete collection of all urine and feces. The patient suffered at times from mild pains, especially on moving about in bed. He remained in bed during the entire period of observation. He received a diet of 2500 calories containing 75 grams protein, and was in a slightly positive nitrogen balance throughout. The calcium in the food was varied from 0.5 to 1.2 grams per day. He required 0.7 gram of calcium (expressed as calcium) daily to maintain balance and with an intake of 0.5 gram per day showed a negative balance. Three hundred and eighty units of parathormone were given between February 16 and March 2 with a maximum daily dosage of 40 units. The patient was more uncomfortable during this medication and hence it was stopped. Moderate constipation was experienced during the first month in the hospital which was readily relieved by strychnine and agar-agar. The patient's general condition improved and on April 23, 1926 he was transferred to the metabolism ward of the Massachusetts General Hospital in the care of Drs. Aub and Bauer.

\section{METHODS}

The calcium and phosphorus intakes were calculated from Sherman's food table as given by Rose (3). Seven diets which duplicated the diets for one day of each period were analysed for calcium and phosphorus. It was found that the calculated amounts of calcium and phosphorus in the diets for the period varied both above and below those of the diets analysed but the average for the daily diets fell within 5 per cent of the amounts found in the diet which was analysed. Therefore, we feel that the calculated intakes represent accurately the actual 


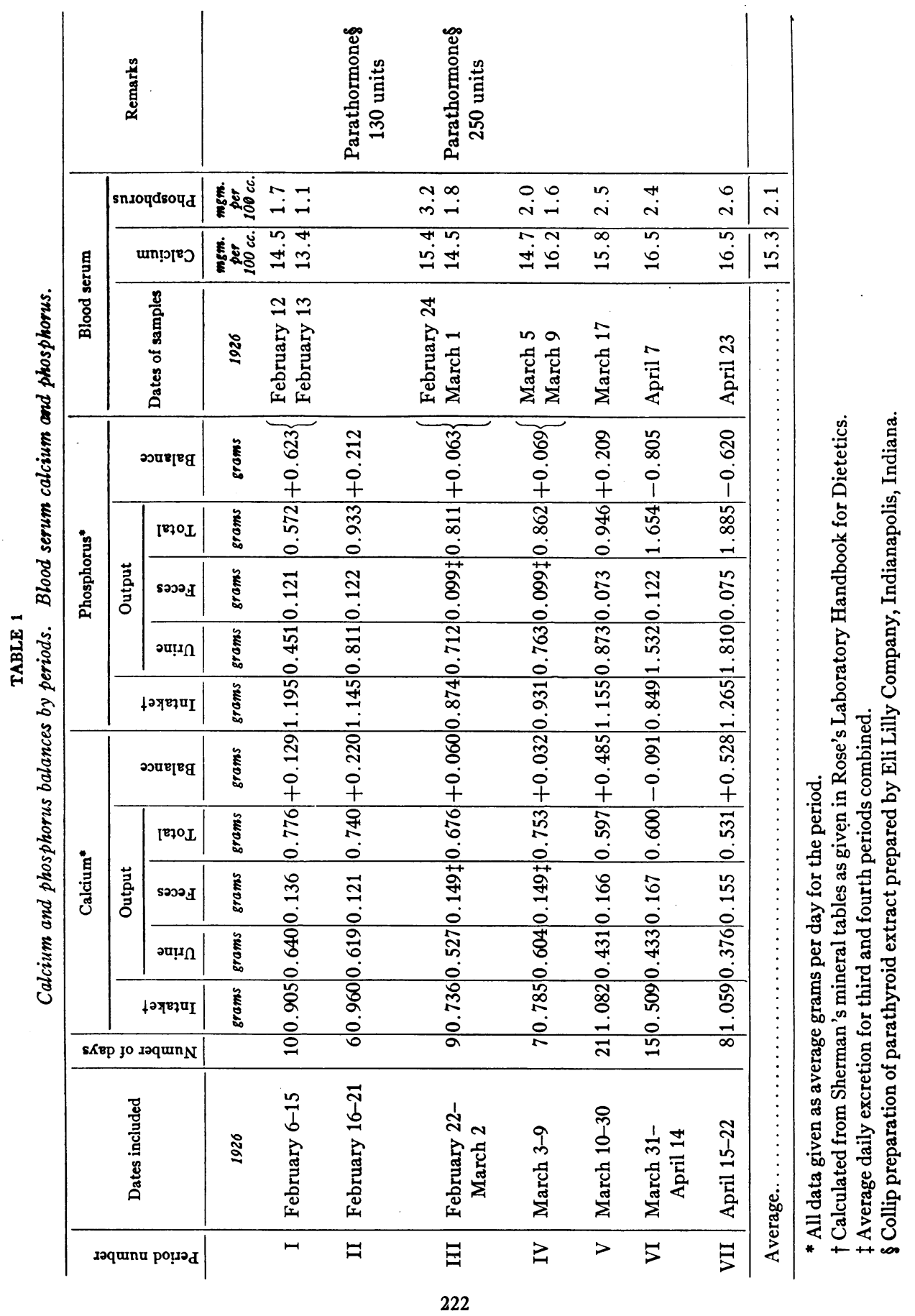


amounts of these minerals ingested. The calcium in the urine was determined by the method of Shohl and Pedley (4) and the phosphorus by the method of Fiske and Subbarow (5). The feces was dried, digested with sulfuric and nitric acids and the calcium and phosphorus determined in the same way as in the urine. The serum was estimated by the method of Kramer and Tisdall as modified by Clark and Collip (6) and the serum phosphorus by the method of Fiske and Subbarow (5). Table 1 contains the blood calcium and phosphorus determinations and the other significant data concerning the calcium and phosphorus balances during the periods of observation.

\section{COMMENTS}

From the clinical and roentgenological studies it seems evident that this is a case of osteitis fibrosa cystica although the differentiation from osteomalacia is not easy. Clinically he had a long history of progressive skeletal deformities with frequent fractures which healed slowly. Roentgenograms showed general rarefaction of the bones with no proliferation and some cyst formation.

At the present time bone is considered an active tissue that is constantly being built up and broken down by osteoblasts and osteoclasts and a part of an interacting system made up of soft tissues, blood, and bone. In osteitis fibrosa cystica, as well as in osteomalacia, osteogenesis imperfecta, and rickets, the essential nature of the pathological disturbance is the laying down of a type of bone deficient in lime salts, called osteoid tissue, in place of normal bone. The similarity of the pathological changes in the skeleton in these diseases has led many to regard them as a single disease with varying degrees of intensity and with different localizations.

The causes of these conditions have usually been classified as exogenous or endogenous. The first group includes malnutrition, lack of specific food factors such as vitamine $\mathrm{D}$, and diets deficient in calcium. In the endogenous group fall repeated pregnancies and protracted lactation, certain pathological processes such as osteomata and myositis ossificans, and disturbances in the glands of internal secretion, particularly the ovaries and parathyroids. McCrudden (2) has discussed most of these factors.

We have found no studies of the mineral balance of patients with 
osteitis fibrosa cystica. ${ }^{2}$ Osteomalacia, however, has been extensively studied in this respect. The most constant findings in osteomalacia are a negative calcium balance and a lowered calcium content of the blood, even when ingesting amounts of calcium which would be adequate for a normal individual. A few cases are reported with elevated blood calcium (2).

The rôle of the parathyroid in calcium metabolism is now well recognized.

a. Hyposecretion, either infantile (tetany) (7), postoperative, or idiopathic, is marked by low blood calcium with elevated blood phosphorus, and increased muscle and nerve irritability as evidenced by the electrical reactions and the occurrence of convulsions.

b. Hypersecretion, studied by the use of a potent extract of parathyroids (8), is distinguished by elevation of blood calcium, a lowered blood phosphorus (later followed by elevation if the extract is continued), and by a negative calcium balance at the expense of the bone calcium (9).

Our patient presented a number of prominent features:

1. Blood calcium. Throughout the period of observation the level was elevated ranging from 13.4 to $16.5 \mathrm{mgm}$. per $100 \mathrm{cc}$. of blood, but usually between 15.0 and $16.0 \mathrm{mgm}$. The normal range is between 9 and $11 \mathrm{mgm}$. (10). This finding is in contrast to the usual level in osteomalacia (11) which is generally lower than normal. They correspond to the figures obtained in animals which received a potent parathyroid extract. Clinically Hunter and Aub (12) found high levels during periods of parathyroid administration in the treatment of lead poisoning.

2. Blood phosphorus. The determinations all fell between 1.1 and

${ }^{2}$ Since these studies were made, three reports of the mineral balance in osteitis fibrosa cystica have appeared: 1. Gold, Wien. Med. Wochenschrift, 1927, lxxvii, 1734; 2. Barr, Bulger, and Dixon, J.A.M.A., 1929, xcii, 951; 3. Wilder, Endocrinology, 1929, xiii, 231. The chemical findings are in essential agreement with those presented by this patient. All three had tumors of the parathyroid bodies which were removed with clinical improvement. Wilder's paper contains an excellent discussion of the rôle of the parathyroid bodies in osteitis fibrosa cystica with a collection of the cases reported in the literature. 
$3.3 \mathrm{mgm}$. per $100 \mathrm{cc}$. and mostly below $2.5 \mathrm{mgm}$. The normal level is between 3.0 and 4.0 (13). This depression in the phosphorus level in the blood has been mentioned by Collip following the administration of parathyroid extract (8). On continued administration of parathyroid extract the animals showed rising phosphorus levels which were marked just before death.

3. Mineral balances. The intake of calcium and phosphorus was entirely supplied from the food. A,daily intake of $0.4 \mathrm{gram}$ of calcium (expressed as calcium) is sufficient to maintain a normal individual in balance (14). Our patient required 0.7 gram per day to maintain him in calcium equilibrium and on 0.5 gram per day he had a definite negative calcium balance. The facts with regard to phosphorus balances are vague. Our patient showed a positive balance for five periods and a negative balance in the last two periods. No explanation for this shift in balance can be offered.

4. Mineral excretion. The normal subject on a general balanced diet excretes in the feces from 70 to 90 per cent of the total calcium eliminated and the remainder in the urine (15). On the other hand our subject excreted only 10 to 30 per cent in the feces and the greater amount in the urine. The low calcium excretion in the feces suggests efficient absorption from the intestine.

5. Parathormone administration. All the medications which have been recognized as of value in treating osteomalacia had been used without success. While he was under careful observation we administered parathormone in small doses, for diagnostic purposes. He received 380 units over a period of 15 days. The clinical effects were striking. He complained of definite increase of pain all over his body, especially on motion. There was in addition, a slight elevation in the blood calcium. The medication was then stopped.

6. Electrical reactions. The muscles generally were flabby and poor in tone. The electrical reactions revealed a marked reduction in excitability of muscle and nerve. This is the exact opposite of the response obtained in hypoparathyroidism (16).

7. Nature of blood clot. The blood clot differed from the usual normal clot. It slowly formed a dark red, very friable clot with very little clot retraction. Serum, free from red cells, could not be obtained except by centrifugalization. This is in keeping with the find- 
ings of Mellanby (17), that an increase in blood calcium concentration lengthens the coagulation time.

Our patient then presents a picture which agrees in its essentials with that produced by the excessive administration of parathyroid extract and opposite to that found in hypoparathyroidism. These considerations and the finding of parathyroid tumors in patients with osteomalacia and similar bone disturbances (18) led us to the conclusion that the underlying basis for the osteitis fibrosa cystica in our subject was a hyperactivity of the parathyroid bodies.

It was obvious that a search for some abnormality of the parathyroid glands was the next step indicated. At the closing of our metabolism ward for the summer the patient was transferred to the care of Drs. Aub and Bauer at the Massachusetts General Hospital for further studies of his calcium metabolism and a consideration of the advisability of removing one or more of his parathyroid glands.

\section{BIBLIOGRAPHY}

1. Oxford Medicine, London, iv, 445 . Osteitis Fibrosa Cystica.

2. McCrudden, F. H., Endocrinology and Metabolism, 1922, iv, 733. Metabolism in Diseases of Bones and Joints.

3. Rose, M. S., Laboratory Handbook for Dietetics, Revised edition, MacMillan Company, New York.

4. Shohl, A. T., and Pedley, F. G., J. Biol. Chem., 1922, 1, 537. A Rapid and Accurate Method for Calcium in Urine.

5. Fiske, C. H., and Subbarow, Y., J. Biol. Chem., 1925, lxvi, 375. The Colorimetric Determination of Phosphorus.

6. Clark, E. P., and Collip, J. B., J. Biol. Chem., 1925, 1xiii, 461. A Study of the Tisdall Method for the Determination of Blood Serum Calcium with a Suggested Modification.

7. Howland, J., and Marriott, W. McK., Quart. J. Med., 1918, xi, 289. Observations upon the Calcium Content of the Blood in Infantile Tetany and upon the Effect of Treatment by Calcium.

8. Collip, J. B., Med., 1926, v, 1. The Parathyroid Glands.

9. Greenwald, I., and Gross, J., J. Biol. Chem., 1926, lxviii, 325. The Effect of Long Continued Administration of Parathyroid Extract upon the Excretion of Phosphorus and Calcium.

10. Kramer, B., and Tisdall, F. F., J. Biol. Chem., 1921, xlvii, 475. A Simple Technique for the Determination of Calcium and Magnesium in Small Amounts of Serum.

11. Miles, L. M., and Feng, C. T., J. Exp. Med., 1925, xli, 137. Calcium and Phosphorus Metabolism in Osteomalacia. 
12. Hunter, D., and Aub, J. C., Quart. J. Med., 1926-27, xx, 123. Lead Studies. XV. The Effect of the Parathyroid Hormone on the Excretion of Lead and of Calcium in Patients Suffering from Lead Poisoning.

13. Hawk, P. B., and Bergeim, O., Practical Physiological Chemistry, 9th edition, Blakiston's Son and Company, Philadelphia, 1926, p. 404.

14. Sherman, H. C., J. Biol. Chem., 1920, xliv, 21. Calcium Requirement of Maintenance in Man.

15. Myers, V. C., and Fine, M. S., Proc. Soc. Exp. Biol. and Med., 1919, xvi, 73. The Relative Importance of the Intestine and Kidneys as Excretory Channels.

16. Holt, L. E., and Howland, J., Disease of Infancy and Childhood, 9th edition, Appleton, New York, 1926, p. 550.

17. Mellanby, J., J. Physiol., 1909, xxxviii, 28. The Coagulation of Blood.

18. Erdheim, J., Über Epithelkörperbefund bei Ostemalacia. Sitzungsberichte der königlichen kaiserlichen. Akademie der Wissenschaft zur Wein. Mathematische naturwissenchaftliche. Klasse, Wien, 1907, cxvi, 3: 311370. (Quoted by McCrudden, Ref. 2, p. 767.) 